\title{
Ministries clash over rival visions of the future
}

Tokyo. The appearance of rival reports published within days of each other in Tokyo by two separate government departments offering very different visions of Japan's future information infrastructure - represents an early skirmish in what promises to be a lengthy struggle.

The reports were drawn up by the Ministry of International Trade and Industry (MITI) and the Telecommunications Council, a high-level committee that advises the Japanese Ministry of Posts and Telecommunications (MPT).

Historically, MITI has overseen Japan's computer industry, while MPT has controlled communications and broadcasting. But the spread of digital technology means that telephones and televisions increasingly resemble computers, and this fact has precipitated an interministerial turf war.

One big difference between the reports is that while MITI's Advanced Informationization [sic] Program focuses on the importance of promoting the use of the network,

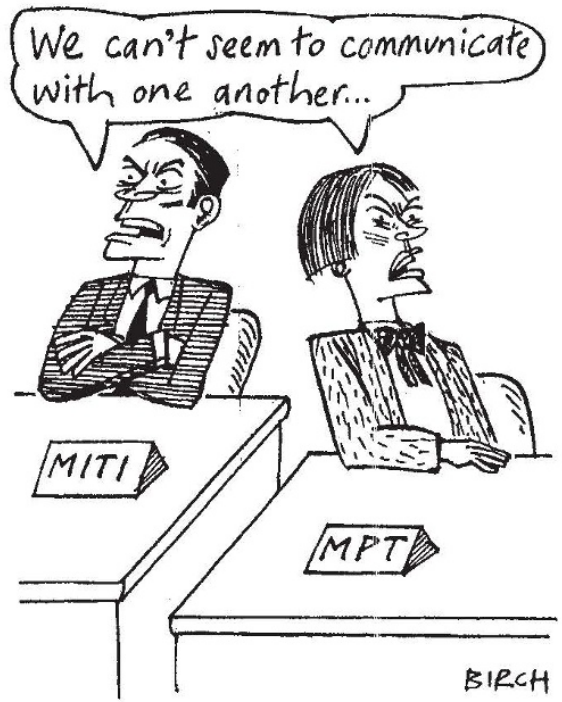

MPT's Establishing a New Information Infrastructure for the 21st Century emphasizes construction of the network itself.

The MPT report envisages a three-stage project to lay optic fibres to all Japanese homes and offices by the year 2010 .

The cost would be between $¥ 33,000$ and $¥ 53,000$ billion ( $\$ 317$ to $\$ 510$ billion). The report makes no attempt to indicate where such huge sums would come from. Nippon Telegraph and Telephone (NTT), Japan's semi-privatized telecommunications giant, has offered to do the job, but only if it is allowed to raise its tariffs, and MPT has recently ruled out such an increase.

The report drew immediate criticism for its insistence that Japan's information infrastructure should be made up exclusively of optic fibre, rather than a mixture of connection schemes including satellite, wireless and copper cable.
Less controversial is its suggestion that, for the sake of efficiency, the network should be built by the private sector, with the government's role limited to providing tax incentives and low-interest loans.

This apparent hands-off policy represents a U-turn from MPT's recommendation last autumn that a public corporation be set up under the ministry's control to do the construction. Since making that proposal, MPT has come under fire - most notably from its former vassal, NTT - for the repeated failures of its dirigiste policies.

Many Japanese now realize that red tape, for which MPT is responsible, is the main reason that their country's cable television and mobile communications industries lag so far behind those in the West.

But some observers wonder whether this enthusiasm of telecommunications officials for private-sector initiatives is as wholehearted as it seems. "They know they have to do some deregulation," says Izumi Aizu of the Center for Global Communications, a small but influential private think-tank. "But if you read the report carefully, it's clear that they want to remain the major player."

Giving the private sector its head through deregulation and liberalization also figures as one of two main themes outlined in MITI's report. The other, according to one MITI official, is that "it is important for government to act as a very advanced user of information technology".

The report's concrete proposals include a recommendation that 100 schools be connected to the Internet to demonstrate the educational benefits of computer networking. In contrast, the MPT report makes no mention of networking.

Emphasizing the use of the network is a new twist for MITI, whose traditional role has been to protect and promote the growth of Japan's domestic computer industry. Shumpei Kumon, a leading Japanese networking advocate, says that MITI seems to have realized that "what is important at this moment is not to protect and promote industry, but to promote the development of networking, using the most advanced technology that can be imported".

But although the bureaucrats have belatedly realized that building an information infrastructure is important for Japan's future, Kumon complains that they still "have no clear vision of what the information revolution means".

Involving schools with networking means that MITI must win the support of the Ministry of Science, Education and Culture for its proposals. The trade ministry is trying to set up an inter-agency task force under the leadership of the prime minister's office to push for further deregulation of telecommunications and the development of networking. Other agencies, including the ministries of education and health and welfare, are said to be enthusiastic about participating in the task force's activities. Only MPT appears reluctant to join.

Bob Johnstone

\section{Wool slump leads to research cuts}

Sydney. Changing national priorities, budget cutbacks and a slump in the Australian wool industry have led to the loss of 138 jobs and 10 research sites by Australia's main agricultural research organization. The cuts were announced by the agricultural research section of Australia's Commonwealth Scientific and Industrial Research Organisation (CSIRO) in a move designed to reduce its A $\$ 126$ million budget by 13 per cent.

Proposals circulated last week to staff of the CSIRO Institute of Animal Production and Processing, which accounts for 15 per cent of the organization's overall budget, would cut overheads by closing down 10 research sites and consolidating operations on the remaining 17 . The institute intends to eliminate 174 positions, including 21 researchers, out of a staff of 1,554 . But some staff and researchers will be re-deployed, and new staff may also be hired, so that the net loss is likely to be 138 staff-- including only three researchers.

Alan Donald, the director of the institute, says the plans have yet to be discussed with staff, and that any proposed budget cuts need the approval of the CSIRO board.

CSIRO itself has had its budget cut this year by A $\$ 20.5$ million (see Nature 369,90 ; 1994), and an internal review of research priorities has led to a decision to shift funds from agriculture into areas such as manufacturing and minerals.

But this will account for a reduction of only A\$5.5 million in the institute's budget. According to Donald, funds from industry are also expected to fall by A $\$ 11.5$ million to A $\$ 22.5$ million, mainly due to a slump in the Australian wool industry.

The shake-up also reflects a shift in CSIRO's priorities within agriculture away from 'production' issues, such as animal health, into 'processing' research - for example, developing ways of making wool more competitive with natural fibres.

The rationalization of sites is expected to include combining the Division of Animal Health's laboratory, at present adjacent to Melbourne University, with the Australian Animal Health Laboratory at Geelong, a regional centre southwest of Melbourne.

Mark Lawson 